\title{
An evaluation of the Development of the People's Network in the North East
}

\author{
Pat Gannon-Leary, Linda Banwell and Sandra Parker
}

\section{The principal author}

Dr. Gannon-Leary is a Research Associate in the Learning and Teaching Support section of the Registrars Department, Northumbria University. She was formerly a researcher in the Information Management Research Institute where she conducted the People's Network research on behalf of NEMLAC. Her research interests include widening participation and diverse student needs.

\begin{abstract}
This research was conducted in response to a brief from NEMLAC requesting a review of the development of the People's Network in the North East region's public libraries with a view to the preparation of an Action Plan. The methodology involved interviews with key contacts in each of the 12 authorities in the North East, questionnaires distributed to users of the PN and brief interviews with customers using the PN in libraries within each authority. An Expert Day was held to which PN managers from the 12 authorities were invited to discuss and contribute to the research findings.
\end{abstract}

\section{INTRODUCTION}

This research was conducted in response to a brief from the North East Museums, Libraries and Archives Council (NEMLAC) requesting a review of current practice regarding the monitoring and evaluation of the value and impact of the People's Network (PN) programmes in the North East region's public libraries with a view to the preparation of an Action Plan.

Measuring the impact of the PN is a current key agenda item nationally for bodies such as DCMS and Resource. This research provides the regionally based data NEMLAC needs to advocate on behalf of the northern library authorities on the national stage. Following the initiatives of recent years such as the DCMS/Wolfson Challenge Fund and monies available from Bill and Melinda Gates, public libraries are now well resourced in terms of ICT provision. However, little work has yet been undertaken to investigate the impact of that provision on the libraries' clients. To have, and contextualise such data, will be imperative for funders at regional and national level to be able to understand the return on their investments, and therefore to plan for the future. This project is important in providing a piece of the jigsaw.

\section{LITERATURE REVIEW}

The New Library: the People's Network report, launched in Oct 1997 (Opening the gates to the New Library? (1997)), recommended that the UK public library service should be linked to the information superhighway by means of a managed network, analogous to the Joint Academic Network (JANET), and that a Public Library Networking Agency be set up to stimulate and coordinate networking developments 
throughout the UK. Chris Smith, Secretary of State for Culture, Media and Sport referred to some of the conclusions of the New Library: the People's Network in his speech at the 1997 UK Public Library Authorities Conference, examining how the public library could respond to the challenge of harnessing information technology. Smith (1997) set this in the context of the cultural sector as a whole, explaining the government's vision for the public libraries sector and its role in delivering wider cultural, social, educational and financial benefits.

Several authors, including Batt (1999) and Hattery (2000) explained the mission of the UK 'People's Network' and its aim of connecting over 4,000 public library service points to the 'Information Superhighway' by the end of 2002, with suitably trained workforce to support and advise users, access to new high quality digital materials to support lifelong learning, and agreed standards of provision. This would involve setting up some 30,000 terminals over two and a half years. Batt (1999) identified 3 elements of the project: a physical access route; an agent for cultural development; and integration of electronic information. He also stressed that, in addition to providing ICT learning centres in each public library, it was necessary to ensure public libraries continued to play a key role in the community, supporting its regeneration, development and well-being.

A major impetus was provided by the training challenge set out in the LIC report: New Library: the People's Network (1997) and the $£ 20$ million Lottery funding to be made available for staff training.

Jones et al (1999) report the results of a one-year public library research project, funded by BLRIC into the impact of new technologies on library staff and ways to reskill the library workforce. This project was the result of a partnership between Birmingham and Shropshire library services, supported and evaluated by the Centre for Information Research and Training (CIRT). The project examined the impact of ICTs on public library staff roles and skills, and the learning possibilities offered by flexible, technology based methods. Results found that most public library staff were exceptionally loyal and committed to the service; there was a great need for staff to gain confidence in the new technology; there were a number of problems associated with ICT training; and there was great awareness of what staff can achieve for themselves if they are provided with tools and training. Beck (2001), reporting on the impact of the UK NOF ICT Training Initiative for public library staff, refers to Belle Associates' 'Learning Line' training programme that helps staff to take responsibility for their own learning while empowering library services to become better learning organizations.

Other references to NOF training include Sharpe's (2001) evaluation of one a year of NOF-funded ICT training, objectives of which were 'to equip public library staff with the skills, knowledge and confidence to use ICTs effectively in their day to day work and ...to benefit the users of public libraries'. Sharpe (2001) considers the practicalities of organizing and delivering training; the impact of ICTs on management and operation of library services; and the effect on user service. He concludes that, despite practical difficulties in organising and delivering such a large scale training scheme within the limited resources available, benefits to staff development and to library services are starting to appear. Raven (2001) presents a 
case study of the implementation of a four year NOF training programme at Lincolnshire Libraries, describing benefits to both local authority and library users.

Against the background of efforts to implement the PN in UK public libraries, Batt et al (2001) examine how far the institution needs to be reinvented in a climate of change and uncertainty, pointing out that planning and options analysis need to respond to factors beyond the requirements of the particular library service.

Boughey (2000) discusses how the PN and other government initiatives have set out a new direction for UK public library service. The aim is to create 'hybrid' libraries, combining existing book lending and information services with extensive ICT access. With the new technology will come enhanced roles in information, learning support and reader development. With respect to the last-mentioned Forrest (2001) expresses a desire for reader development to happen concurrently with the putting in place of the PN to improve the image of library services and attract new users

Stoker (2000) discusses the degree to which access to ICT in the UK, in particular the Internet, is likely to erode the differences between the information-rich and information-poor in society. Reference is made to the report by Policy Action Team 15 (2000) and the ways in which ICTs can help people in disadvantaged communities, through the agency of public libraries are listed. With respect to lifelong learning Todd and Tedd (2000) briefly review opportunities in the UK through initiatives such as the National Grid for Learning (NGfL) and the University for Industry (UfI) prior to a review of how public libraries can be involved in the process of providing ICT training courses for lifelong learners. Lifelong learning opportunities are now being provided outside of the public libraries by supermarket chains (Harwood (2002) TES (2002)) and, given this trend, questions may be raised as to how far the placement of PN machines in supermarkets would be more effective in reaching non-users than their placement in public libraries. It is important that the public libraries justify their $\mathrm{PN}$ allocation and evaluate the use made of the service through research such as this.

\section{METHODOLOGY}

The project methodology is based on the principles of iterative user-centred design, where the stakeholder community has a major role at all stages of the project.

In-depth fieldwork was undertaken in the 12 authorities. One day was spent by the researcher in each authority to obtain a snapshot of activity across the North East in relation to the PN. A brief questionnaire was supplemented by on-site observation and brief random interviews with PN users. Data recorded was both quantifiable and anecdotal, in order to give the holistic picture required. The outcome of this first phase of data analysis was used to monitor and evaluate the PN from the library clients' points of view. This formed the basis for discussion at an Expert Day, held at NEMLAC, with an invited audience made up of the project team, project stakeholders and library staff from the authorities. Discussion was used to validate and extend the dataset. As a result of this research activity an action plan was drawn up by the research team.

\section{RESULTS}

Fifty questionnaires were distributed to each of the twelve authorities. The mean number of responses per authority was 38.5 . The response rate was a gratifying $77 \%$ 
and the authorities are to be congratulated on the effective distribution and receipt of the questionnaires.

\section{Respondents by gender \& age}

$58.6 \%$ of respondents to the questionnaire were male and $41.4 \%$ female. The largest number of users (44\%) responding to the questionnaire was in the 16-35 age bracket. The second largest group (26\%) was the $36-55$ with $18 \%$ of respondents being over 55 and $12 \%$ of respondents being under sixteen.

Figure 1 - respondents by gender \& age

$$
\text { age }
$$

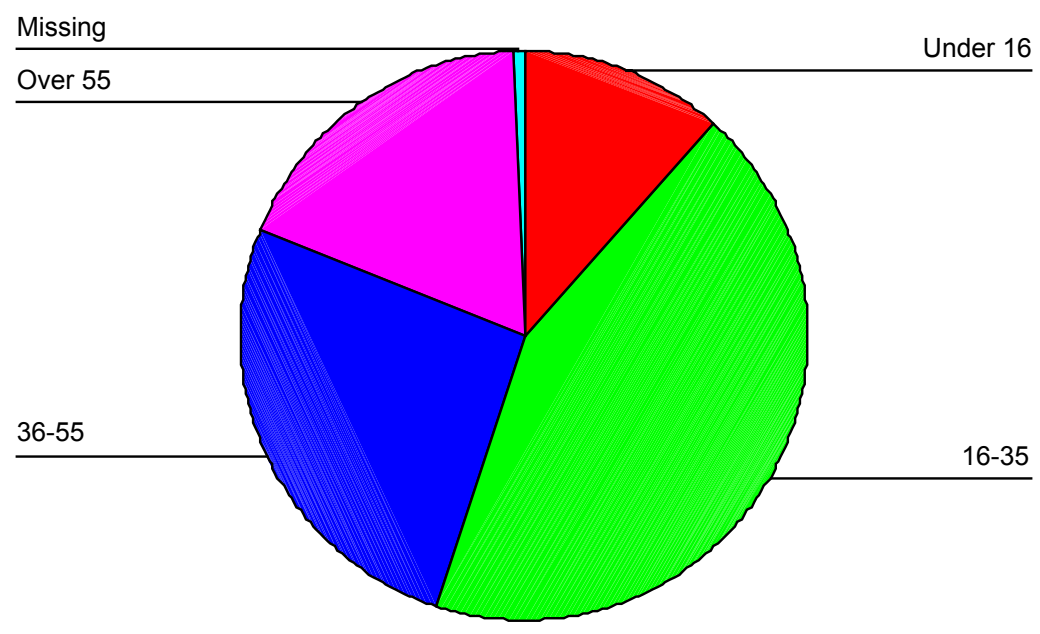

\section{Respondents by status}

$26.6 \%$ of respondents to the survey were students. The next largest group (22\%) was unemployed. $17.4 \%$ of respondents were in full-time work, $16.4 \%$ retired, $15 \%$ in part-time work, $1.5 \%$ students who were also working part-time and $0.75 \%$ were selfemployed.

Figure 2 - respondents by status 


\section{Status}

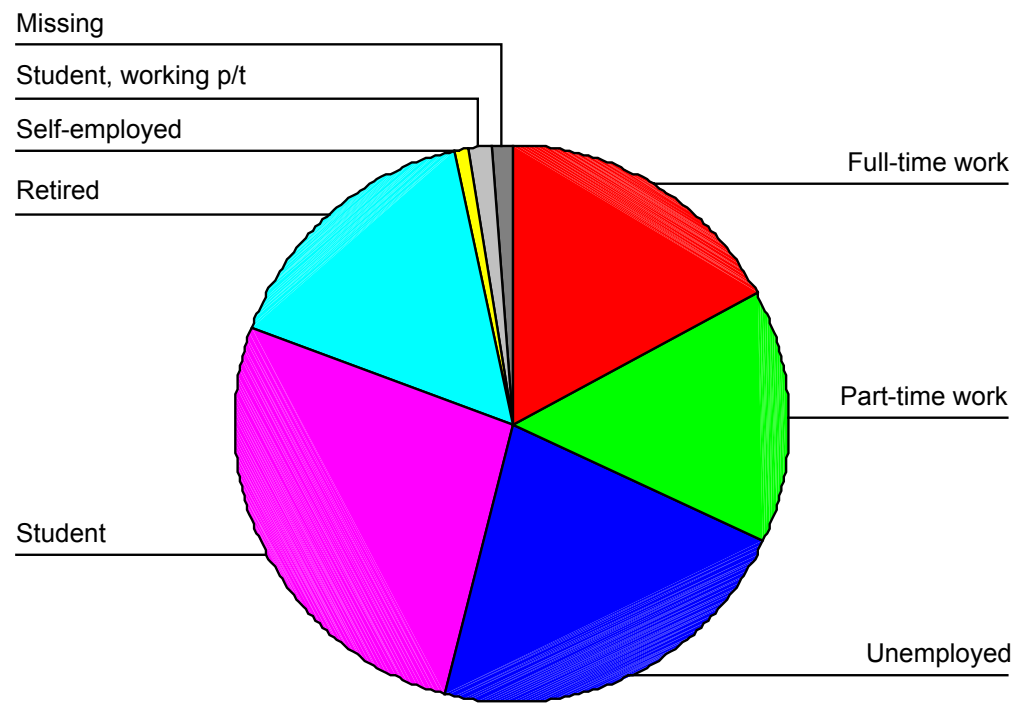

Although the questionnaire had asked for information about ethnicity the figures in these categories were too low to represent in tabular form. Out of 334 respondents who gave the ethnic group to which they belonged, 298 (i.e. 89.2\%) were white. 10 were black African, 5 Indian, 4 Chinese, 3 each Bangladesh and Black other than African and 2 Pakistani.

\section{Respondents with a disability}

$7.9 \%$ of respondents said they considered themselves to have a disability. The second largest percentage of disabled respondents was from a case study site which had the best software provision for visually impaired customers.

\section{Uses made of PN PCs}

$69.5 \%$ of respondents said they were using the PN PCs to search the Internet for a specific subject. $64.25 \%$ were using e-mail. $44.6 \%$ were using a specific Internet site. $21 \%$ were word processing and $4.3 \%$ were shopping on the Internet. Other uses made by respondents included playing games, communicating via fora or chat rooms (where this was allowed by authorities), desk top publishing, updating websites and using a database. $71.25 \%$ of respondents were using the PN PCs for pleasure. 50.5\% said they were using them for independent learning or research while $29 \%$ were using them for a course of study. Other reasons listed by respondents included job hunting, house hunting, holiday hunting, shopping, work-based activity and communications.

Figure 3 - uses made of PN PCs 


\section{Reasons}

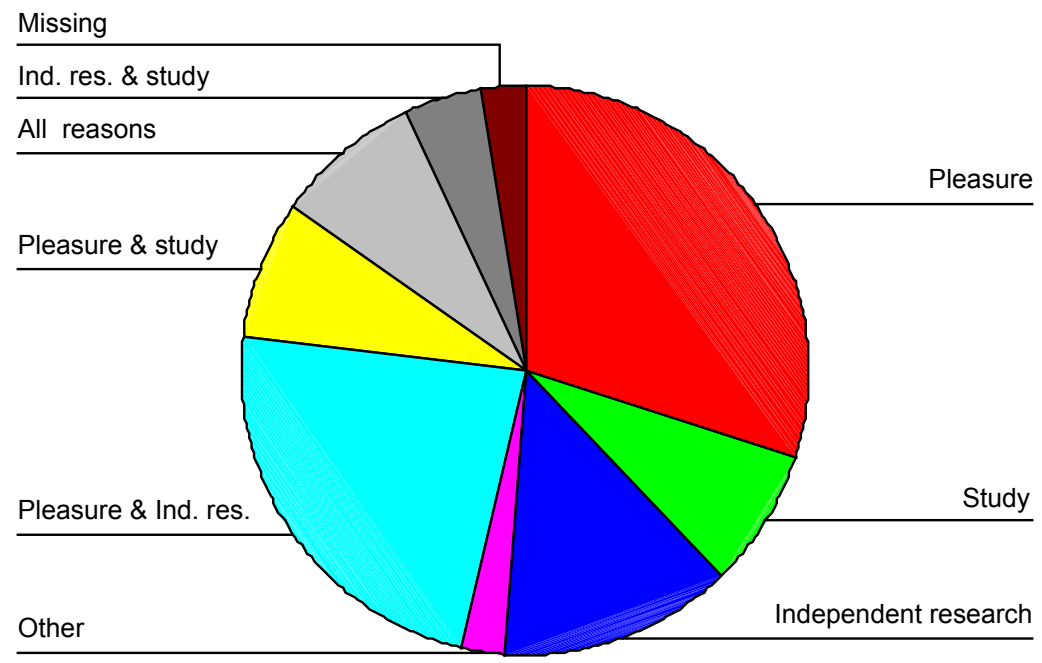

\section{Reasons for using the Library's PCs}

$60.85 \%$ of respondents used the PCs in the library because they had no computing facilities at home. $57.85 \%$ used them because the service was free and $17.7 \%$ used them because of the software available. Other reasons given for using the PCs in the library included the availability of the Internet, the speed of the connection, the fact the library PCs were a better spec than home PCs, the availability of staff support or tuition, ease of access, privacy and security in the library and the fact it was too noisy at home!

Figure 4 - reasons for using the Library's PCs

\section{Library}

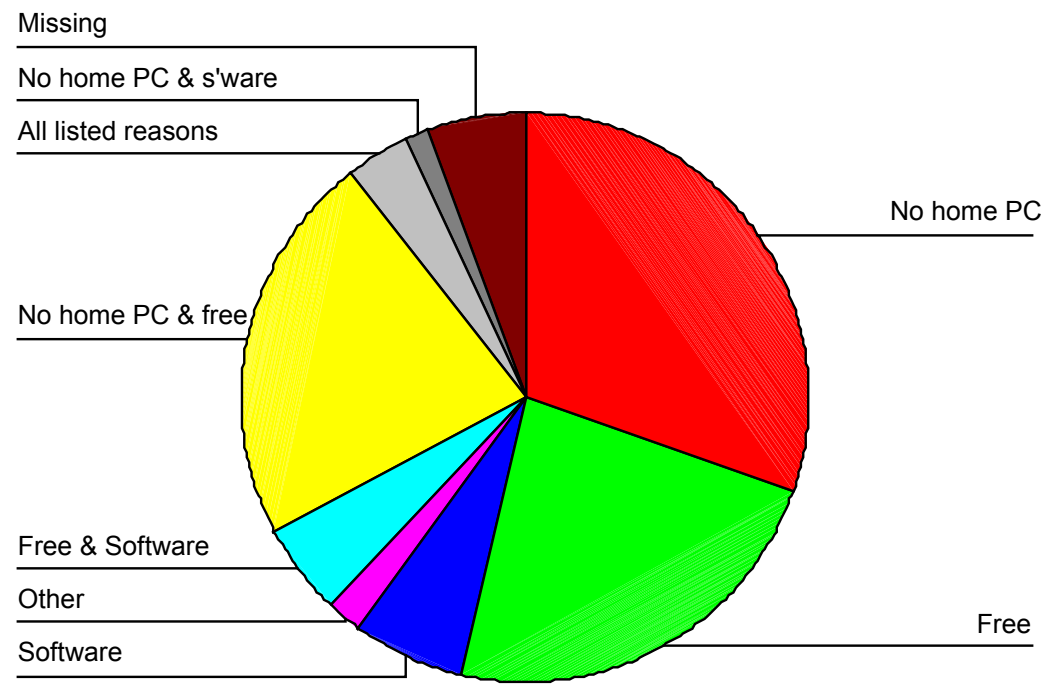




\section{Frequency of use of PN PCs}

$46.5 \%$ of respondents reported using the PN PCs two to three times a week. $24.25 \%$ used them once a week. $14 \%$ used them daily while $8.75 \%$ used them once a month. $6.5 \%$ reported that they used the PN PCs less often than once a month.

Figure 5 - frequency of use of PN PCs

\section{Often}

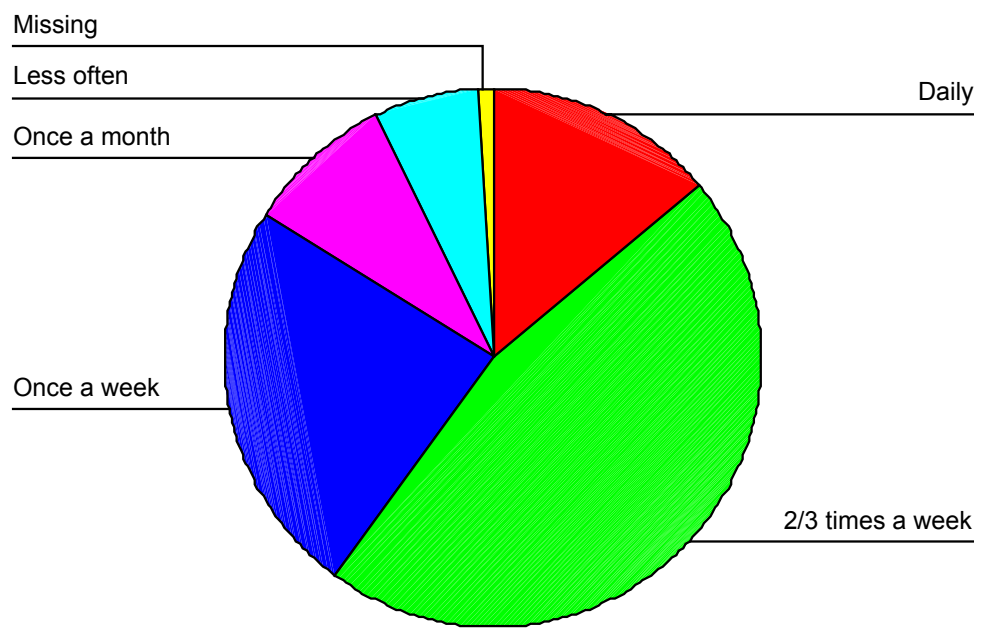

\section{How useful users rated the PN PCs}

$82 \%$ of respondents said they found the PN PCs very useful while $15 \%$ found them fairly useful. Only 3\% thought the PN PCs could be improved. Improvements suggested by respondents included accessibility to more programs, greater speed, less filtering, more time, more assistance, more privacy and, in cases where chat rooms were banned, introduction or reinstatement of this facility.

\section{Skills levels of users as reported by them}

$57 \%$ of respondents believed their IT skills levels to be intermediate. $27 \%$ classified themselves as beginners while $16 \%$ believed they had advanced IT skills.

From the point of view of targeting training it may be useful to know the characteristics of those who considered themselves beginners and at intermediate level. $61.2 \%$ of under sixteens believed they had intermediate IT skills, $24.5 \%$ thought their skills advanced and only $14.3 \%$ considered themselves beginners. In the 16-35 age range, $62.15 \%$ considered themselves intermediate while $19.45 \%$ considered themselves advanced and a further $18.4 \%$ rated themselves beginners. In the $36-55$ age group $52.7 \%$ said they were intermediate in IT skills levels, 31.8\% believed they were beginners and $15.5 \%$ claimed to have advanced skills. In the over 55 age group, $47.4 \%$ of respondents believed themselves to be IT beginners, $47.4 \%$ said they had intermediate skills and only $5.2 \%$ rated themselves as advanced.

$55.75 \%$ of male respondents said their IT skills were intermediate with $25.25 \%$ saying they were at beginner level and 19\% saying they were advanced. In the case of 
female respondents, 57\% thought they had intermediate IT skills with $30 \%$ assigning themselves beginner status and $13 \%$ claiming advanced status.

Figure 6 - Skills levels of users as reported by them

\section{Skills level}

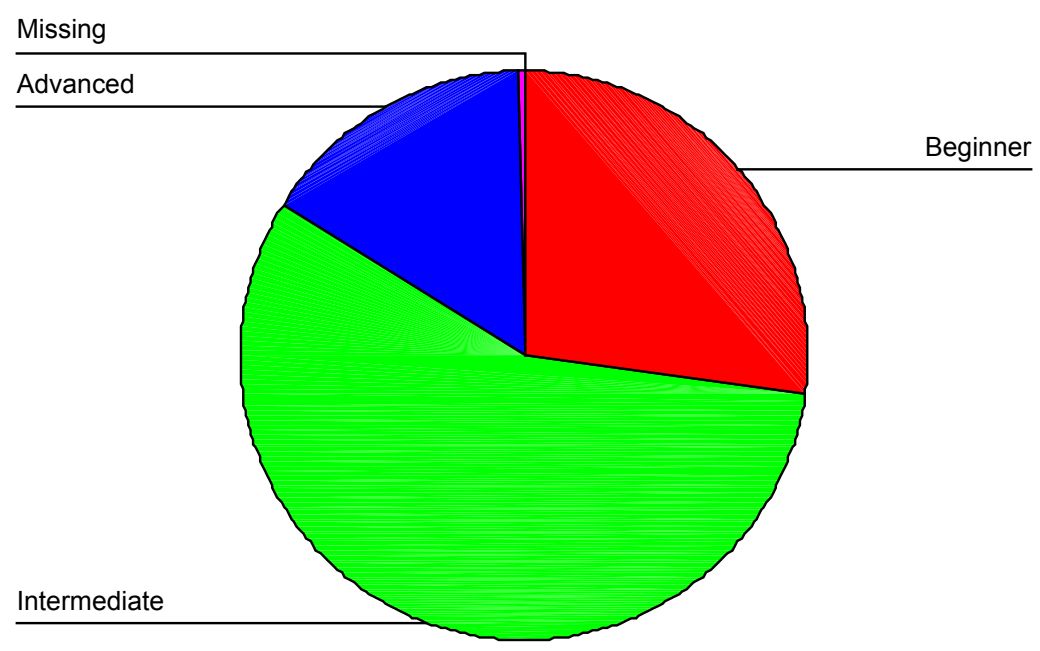

\section{Results from interviews and focus groups}

The following are key themes which emerged from interviews and focus groups with library personnel within the 12 authorities.

\section{PN provision}

The lack of specific identification of the PN provision in several authorities might make it more difficult to disaggregate findings about usage relating specifically to the $\mathrm{PN}$ and therefore to assess its value and impact as distinct from the value and impact of ICTs generally. Much PN kit was still being rolled out, distributed and possibly reassigned during the research period meaning that it was somewhat early to assess the value and impact although findings could be used as a baseline against which results of future research are measured.

In those authorities with a history of ICT provision availability of additional software was likely to add to the value and impact since it should appeal to a wider public. Lack of assistive technology in some authorities may restrict access by customers with special needs. Imaginative uses of videoconferencing and web cams need to be investigated to maximize value and impact of these facilities.

\section{Administrative arrangements}

Any charges levied are likely to affect the value and impact of the PN since they erect a barrier. The socially excluded may find they cannot avail themselves of the full range of services. Booking systems provide usage data linked to the PN although how far such data is likely to measure value and impact is questionable. Having to 
book machines may be regarded as bureaucratic by some would-be PN users who may be deterred by such systems so decreasing the PN's value and impact.

\section{Policies and procedures}

The more policies there are in place, the more barriers may be erected. Some filtering systems seemed over vigilant while others were not sufficiently effective. Several questionnaire respondents were critical of net nannies and the inability to access bona fide websites. Restrictions on access may lessen the value and impact of the PN and restrictions placed on children's usage of the PN may mean that those children whose parents are not supportive of their using ICTs are disadvantaged. Insistence on membership may smack of bureaucracy and militate against usage of the PN with subsequent diminution of value and impact.

\section{Promotion of the PN}

Without promotion the chief users of the PN are likely to be those who are already library users or those undertaking ICT training referred to the service by their tutors, i.e. they are largely 'preaching to the converted'. Most authorities had in mind target groups - particularly current non-users of the service - which they would like to reach with their promotional activities. Only with the inclusion of such groups will the true value and impact of the PN be measurable.

\section{Training and support}

Staff were available to support not to train PN users so were not using the full range of skills they had learned. Training was not always timely and relevant. Although staff had reportedly acquired confidence by undertaking the training they were unlikely to be able to use it fully given staffing and time constraints especially in small branches.

Without dedicated ICT support personnel in libraries, actively encouraging people to use the PN, the full potential will not be realized. One interviewee mentioned how many customers "sidle past the computers and, because the staff have a rapport with visitors, they will notice this and invite them to look at the PC or refer them to it in a roundabout way, e.g. if they have a query try to deal with it on the PC". Without this degree of intervention many customers will not use the PN.

\section{Monitoring usage of the PN}

Some anecdotes were provided by library staff based on experiences of their customers about which they had heard. However, because libraries don't require customers to tell them what they are using the Internet for, there are many untold stories. As one member of LIS staff said, "There are all sorts of uses we just don't know about or cannot imagine."

In respect of monitoring value and impact local authorities had some way to go. Lack of monitoring means lack of knowledge of user needs. Qualitative data needed to be collected to help in the measurement of value and impact. Overall users were satisfied with the service and, in the brief period allowed for the research, the researcher acquired much anecdotal material. Such data is available therefore and would assist greatly in the measurement of value and impact but some mechanism needs to be in place so that opportunities to record such rich data are not missed. 


\section{EXPERT DAY ISSUES}

At the end of the project an Expert Day was held at NEMLAC's headquarters with an invited audience of representatives from the 12 authorities. After a presentation on the research progress to date the participants engaged in group work. They were asked firstly to brainstorm key issues associated with the PN. Thereafter they were asked to prioritise these issues. Subsequently the groups brainstormed the inhibitors to successful implementation of the PN and then prioritised these. Finally they had to suggest critical success factors for the PN and these too were prioritised.

\section{Staffing}

Training was identified as the key to making the PN work as was the synchronization of staff training with the PN. Secondly it was felt authorities should be allowed to use PN funding for staff training.

\section{Marketing}

Thirdly there was concern that there was no "joined up" branding and that the PN needed a "big bang" launch. In an ideal world there would have been training closely followed by installation and then the launch. Unless promotion was ongoing it was pointed out that libraries reach neither the people nor the funders who seed corn the growth.

There was a lack of national co-ordination and of regional cooperation, e.g. in purchasing additional systems such as those for booking PN sessions. There are about 400 local authorities in the UK and all are looking at websites, book marking favourites etc. There had been no coordination from the outset so that everyone was doing the same, finding out what products were available etc. Eventually they need to come to some sort of cooperative arrangement instead of all doing everything so some are doing particular areas for the rest.

\section{Time}

The last issue identified was that there had been insufficient time within the three years to roll out the PN. By the time submissions had been approved and points clarified the PN was not really a three-year programme.

\section{Inhibitors}

The chief inhibitors were identified by Expert Day participants as, firstly, staff resources and the need for support and training for staff confidence and, secondly, sustainability. Staff needed to be confident and proactive rather than reactive. They also had to be able to make the switch from traditional library services to a service enhanced by the PN. In respect of sustainability, it was pointed out that some authorities that were quick off the mark with ICTs are finding it hard to find the funding to continue. In some cases the authority will be providing some money but where is the rest coming from? One interviewee commented that, faced with the option of having "a pool of dying PCs" or "pulling the plug on them" he would go with the latter. PN funding runs out the end of March 2003 and some authorities may have to start charging again. Resource is discussing additional funding to extend the facility. 
Staff training links in with sustainability in that staff on low pay (grade 1) are acquiring IT skills and are leaving to move into other better-paid sectors.

\section{Buildings}

Inhibitors considered important rather than very important included, firstly, the nature of library buildings and their physical restrictions. Participants thought libraries should get less "hung up" on bringing people into libraries and think more about getting services out, including having a virtual library on the web. Space and layout restrictions did, however, make it difficult for libraries to offer different environments to match different user needs and different group uses.

\section{Image}

Secondly, an inhibitor might be the image of "fuddy duddy books" which was in conflict with "brash technology" with the result that the library's image could inhibit PN use and, conversely, the PN image could inhibit use of the library. Both images, it was felt, needed addressing.

\section{External restrictions}

A third inhibitor was external restrictions related to audit and performance indicators, i.e. the actual collection of data. New borrowers registered to libraries provided a performance indicator, hence the desire for would-be PN users to become library members. If a PC was "issued" to a user via a booking system this gave libraries higher issue statistics.

\section{Critical success factors as perceived by the librarians}

Finally the Expert Day participants were asked to identify critical success factors (CSFs) associated with the PN and to prioritise these.

The first CSF identified was a guaranteed funding stream with the second being a high profile. These two were prioritized by more participants than any of the other CSFs. The third CSF was training staff to facilitate PN usage, followed by the fourth, being flexible and open with free access. Under the PN, authorities could charge if they wanted to whereas the Gates funding, e.g., was dependent on the service being free. The fifth CSF was continuing to be relevant and avoiding reinventing the wheel was assigned equal fifth priority. Libraries should be working together nationally to develop and buy content thereby achieving economies of scale.

In equal sixth place among the CSFs were attracting new customers, evolving rather than remaining static and engaging in performance measurement which was qualitative as well as quantitative. The final CSF was engaging in partnerships that linked to the aforementioned achievement of economies of scale by cooperative purchase etc.

\section{Rationale}

Data collected during research activity were interpreted by the Research Team to form the Action Plan for the Sustainability of the People's Network in the North East which was presented in tabular form to NEMLAC and will be made available on the website. The key recommendation of the research is the establishment of a People's 
Network Group (PNG), with representation from each authority, to promote a sense of corporate enterprise for the PN by implementing the recommendations of the Action Plan.

\section{Marketing}

The Expert Day identified marketing as an important issue. Branding of the PN is seen to be an essential part of its success and sustainability. Attendees felt very strongly that Resource needed to be aware of the necessity to brand the PN in a way that will fix the concept in people's imagination linking it to the recognised strengths of the public library

Buildings were seen as inhibiting marketing. Recommendations were that, where possible, a cyber café and mall approach was adopted with workstations being available throughout libraries and not merely concentrated in one place. It was perceived that there is a possible conflict with other commercial and public suppliers and that the public libraries' unique selling point is, as it always has been, information evaluation and user support.

\section{Funding and sustainability}

Issues regarding sustainability were thought to be urgent and important. It was felt that the cost of maintaining the PN should not be taken from already hard-pressed local authority funding. Money would be needed for capital expenditure for acquisition and replacement of both hardware and software. Revenue would be needed for content development in addition to licences and fees. It is imperative that the service remains authoritative and up to date.

Staff release for training was thought to be the most important aspect of the critical success factors and this would need continual revenue. The Government wishes to ensure the effective dissemination of e-government materials and it was felt that money for these services should come directly from national government rather than via local authority resources. Citizens need to be educated to use such media and this cost too should fall to national government, not to hard-pressed local authorities.

Making the case for sustainability of the PN will need constant performance measurement both qualitative and quantitative. This can best be achieved by the existing NOF evaluation, which should be supplemented by annual anecdotal evidence.

Collection of anecdotal evidence was seen as key but difficult in a busy library environment. Staff needed to understand what constituted an anecdote and what was worth recording. Staff training was thought necessary to accomplish this.

An important aspect of sustainability will be the creation of partnerships - public, private, within local authorities and across authorities.

A recommendation was that DCMS needs to develop a Joint Information Systems Committee (JISC) for public libraries. The JISC is a strategic advisory committee working on behalf of the funding bodies for further education (FE) and higher education (HE) in the UK. Its central role ensures that the uptake of new technologies and methods is cost-effective, comprehensive and well focused. Since membership of 
the JISC and its committees comprises senior managers, academics and technology experts from across the education sector, there are strong community links, ensuring the JISC remains responsive to the changing needs of the FE and HE sectors.

A strategic option would involve the public library equivalent of JISC Regional Support Centres (RSCs), funded from the DCMS, administered through Resource to NEMLAC with additional income from the NEMLAC grants programme and the NCL group. The RSCs promote and support the use of network learning technologies and resources in the UK FE sector and work with other regional bodies and organisations to develop and publicise a coherent regional programme of activities to support the development of e-learning and continually monitor, evaluate and improve their quality of service. They achieve this, in partnership with other JISC services and organisations, by working with technical, teaching, learning resources and management staff in FE colleges.

\section{Staffing}

Staff were seen to be the most essential aspect of the PN delivery. It was thought vital that skills continued to be updated and new staff trained. Further training was needed in customer support and continuous training was necessary, on a weekly basis, in Internet resources. A major issue for most service points was the release of staff to undertake training and the maintenance of library provision.

Some staff develop skills which could be used in customer training but the support role is that which is stressed with training by LIS staff confined to taster sessions. The support role is comparable to the traditional role in answering enquiries. Staff time and the number of staff available may dictate how long a member of staff can spend helping novice users.

Retention of well-trained library staff is becoming an issue as salaries are so low in the sector in comparison with highly trained IT staff in other areas. This issue needs to be addressed urgently.

Only where IT support personnel are available at branches is it possible for staff to actively encourage use of the PN.

Where one does not already exist, a new post of learning support officer needs to be developed.

\section{Social Inclusion and Lifelong Learning}

These issues are at the heart of the Government's agenda and their investment in the PN. Some of the practices that were in evidence during the fieldwork inhibited full and open access to the services offered. The key factor appeared to be that of charges which it was felt should be resisted at all costs. It was recognised that some authorities felt that they had to charge for some aspects of the PN as there was too much pressure on their global budget to do otherwise.

Some libraries insisted that users of the PN became registered users of the library. It was felt that this is not in the spirit of social inclusion as the homeless, asylum seekers and other displaced persons often cannot produce sufficient evidence of accommodation addresses to satisfy audit requirements. 
Booking procedures were often bureaucratic and potentially excluded some people. Some libraries had simplified booking systems and some had none at all, thus encouraging open access.

It became obvious that partnerships with Adult and Further Education were very important and that each could support clients in very different ways. It is useful to target individual groups and to be proactive in encouraging IT literacy. Some libraries had appointed learning and access officers to encourage this process. One library had an IT customer training team who visited branch libraries and worked with branch library staff in delivering training which encouraged role confidence.

Work in this area should be creative and purposeful. In order to promote it libraries needed a set of diverse testimonials indicating that libraries fill the gap between formal and informal education. Anecdotes are needed to promote this hugely important role of the $\mathrm{PN}$.

\section{Performance Measurement}

There was some debate as to how far booking systems could provide evidence to support the continuing existence of the PN. To recommend that local authorities institute data collection and suggest the optimum booking system for achieving this would be premature at this stage. The PN set-ups in authorities are not yet fully formed and, because of the variety, it is difficult to state that a booking system would be the best way to accrue data. More appropriate would be the recommendation of data collection on the scale of the present research. This could be conducted every two years and action research on specific issues could be carried out in between this longitudinal research, e.g. one piece of action research could be targeted at booking systems. Features such as pop-up random questionnaires on the front end of PCs should be discussed with vendors of library management and booking systems.

\section{A People's Network Group (PNG)}

At the Expert Day it became apparent that PN managers did not meet regularly, although they might see each other on an individual basis. There was, in consequence, no sense of corporate enterprise. There is recognition that there should be a regional voice for the $\mathrm{PN}$ in the form of a regional group with responsibility for the PN under the aegis of the NCL. It is therefore recommended that the NCL establish a PNG which would enable all the issues discussed in the Rationale to be addressed within the context of the local chief librarians' group.

The PNG would be comparable to the Northern Training Group (NTG) which has proved itself, over 20 years, to be an effective tool with respect to training across the sector. The PNG should be as effective as - or more effective than - NTG with comparable status. It should reflect the same partnerships as the NTG, involving NEMLAC which can bring a regional dimension to the group plus a knowledge of funding streams, ICTs and access and learning issues. It might be expanded to include representation from the HE sector where there is expertise in toolkits, learning packs etc. 
The PNG's terms of reference should include the collection of a model set of key data agreed by the membership and the discussion of all aspects of the PN, including monitoring and evaluation. The PNG would report six monthly to NEMLAC and the NCL, providing four to five pages on the developments in the PN, including qualitative snapshots. The chair of the PNG should be a strategic thinker with a clear and dynamic vision of the future of the PN.

\section{References}

Batt, C. (1999) The People's Network: the final frontier Public Library Journal; 14 (4) Winter, p.103-4

Batt, C., Potts, D. and Woodhouse, S. (2001) A changing landscape Public Library Journal; 16 (4) Winter, p.125-6, 128

Beck, J. (2001) Learning to learn Public Library Journal; 16 (3) Autumn, p.67-8, 701

Boughey, A. (2000) Implementing the 'New Library: The People's Network' and the management of change Aslib Proceedings; 52 (4) Apr, p.143-9

Forrest, T. (2001) Who's afraid of those declining adult issues? Library Association Record; 103 (3) Mar, p.168-9

Harwood, J. Milk, eggs, IT skills... Times Higher $15^{\text {th }}$ November 2002, 8-9.

Hattery, M. (2000) The People's Network: public libraries take a central role in getting the UK online Information Retrieval and Library Automation; 36 (5) Oct p.12

Jones, B; Sprague, M; Nankivell, C; Richter, K (1999) Staff in the new library: skill needs and learning choices. British Library Research and Innovation Report; (152).

New library: the people's network (1999) British Library. Research and Innovation Report; (166) p.118-21

Opening the gates to the New Library? (1997) Library Association Record; 99 (11) Nov p.575

Policy Action Team 15 (2000) Closing the digital divide: information and communication technologies in deprived areas. http://www.pat15.org.uk/ (Accessed 29/11/02)

Raven, D. (2001) The big training boost Library Association Record; 103 (10) Oct p.620-1

Sharpe, D. (2001) Progress and pitfalls Public Library Journal; 16 (2) Summer, p.54-5

Smith, C. (1997) Our oyster Public Library Journal; 12 (6) Nov/Dec, p.117-20 
Stoker, D. (2000) Social exclusion, 'joined-up government', public libraries and the Internet Journal of Librarianship and Information Science; 32 (2) Jun, p.53-5

Taste the difference with some IT Times Educational Supplement, $15^{\text {th }}$ November, 2002, 20.

Todd, M. and Tedd, L.A. (2000) Training courses for ICT as part of lifelong learning in public libraries: experiences with a pilot scheme in Belfast Public Libraries Program; 34 (4) Oct , p.375-83 